\title{
Os gregos nas estratégias argumentativas de John Dewey
}

\author{
Marcus Vinicius da Cunha \\ Leonardo Freitas Sacramento
}

Universidade de São Paulo, Faculdade de Filosofia, Ciências e Letras de Ribeirão Preto

\section{Introdução}

Este trabalho decorre de pesquisas que têm por objetivo compreender o modo como determinados pensadores da educação apropriam-se das idéias de outrem, em benefício das teses que desejam transmitir a seus leitores. Segundo o estabelecido por Cunha (2005a), o fenômeno da "apropriação" expressa um empenho "recontextualizador" que consiste em deslocar idéias de um tempo e lugar originais, descontextualizando-as, num primeiro momento, e recolocando-as em outro tempo e lugar, no intuito de torná-las adequadas às concepções que um orador pretende comunicar a seu auditório.

Nessa linha de investigação, considera-se que toda teoria educacional contém articulações discursivas que remetem a contextos sociais, culturais e políticos situados em momentos históricos pretéritos, ou mesmo atuais. Nesses contextos encontram-se as formulações com que o teórico dialoga para construir suas teses originais, com as quais busca redirecionar o pensamento acerca da educação e das ações empreendidas em situações escolares concretas. Assim, para compreender as teorias pedagógicas, faz-se ne- cessário investigar, em seus corpora argumentativos, a interlocução que mantêm com outras concepções educacionais, buscando apreender precisamente a forma e o conteúdo das apropriações que elaboram.

A fundamentação teórico-metodológica para a análise desse processo, igualmente adotada no presente escrito, encontra-se no estudo das práticas retóricas e dialéticas, conforme desenvolvido por Perelman e Olbrechts-Tyteca (2002), e na crítica da forma silogística, elaborada por Toulmin (2001). Esses instrumentos analíticos permitem desvendar em quaisquer textos, e nos escritos educacionais particularmente, as tramas discursivas empregadas por seus autores para veicular os ideários que desejam ver aceitos por seus leitores.

No presente trabalho, o que está em causa é o pensamento filosófico e educacional de John Dewey, no qual se apresentam enunciados passíveis de serem discutidos perante a vida social, as práticas educacionais e a visão de mundo dos gregos da era clássica. ${ }^{1}$

${ }^{1}$ Sendo impossível oferecer aqui uma visão mais geral do pensamento deweyano, remetemos o leitor aos trabalhos de Amaral (1990), Cunha (1994, 2001) e Murphy (1993). 
Tal sugestão decorre do trabalho de Cunha (2005b), que indica haver várias críticas aos gregos nas obras deweyanas, mas também indícios de proximidades com certas noções de Aristóteles, o que sugere a importância de investigar essa temática de maneira mais extensa e aprofundada. ${ }^{2}$

Este artigo tem o propósito de contribuir nessa direção, buscando ampliar o universo de análise do pensamento deweyano e abrir caminho para a compreensão das estratégias discursivas do autor. Para isso, elegeu-se como objeto de estudo o livro Democracia e educação, de 1916, obra capital de Dewey. ${ }^{3}$ $\mathrm{O}$ procedimento da pesquisa consistiu em registrar todas as passagens do livro em que consta alguma referência aos gregos, como a denominação de filósofos e a alusão a processos da vida social em torno dos séculos V-IV a.C. Em seguida, foram identificados os temas em discussão, os quais foram situados no âmbito mais geral das proposições do autor, nas quais, por sua vez, buscou-se identificar as técnicas argumentativas empregadas.

A abordagem adotada neste trabalho não visa "julgar" Dewey, a título de "denunciar" os seus raciocínios, mas simplesmente elucidar os meios pelos quais o seu discurso se faz persuasivo. O propósito almejado nesse tipo de investigação é compreender os recursos postos em ação quando um autor se dispõe a expor determinadas teses de maneira que as torne aceitáveis perante o auditório que pretende atingir. Com isso, espera-se que esse auditório - neste caso, os leitores de Democracia e educação - tome ciência das estratégias discursivas a que está sujeito, poden-

${ }^{2}$ No grupo de pesquisa "Retórica e Argumentação na Pedagogia”, a que se filiam os autores deste artigo, trabalham nessa mesma direção as doutorandas Rita Pimenta de Araújo, que analisa Lógica - teoria da investigação, e Viviane da Costa, que discute o ceticismo deweyano em A busca da certeza.

${ }^{3}$ Nesta pesquisa foi utilizada a terceira edição brasileira de Democracia e educação (Dewey, 1959) e, para dirimir eventuais controvérsias acerca da tradução, a edição em língua inglesa (Dewey, 1997). do com elas interagir. Afinal, esse é o requisito indispensável para que se inicie o debate intelectual qualificado, em qualquer área de conhecimento.

O livro Democracia e educação é composto por vinte e seis capítulos, sendo que em doze deles há alguma menção ao mundo grego. Essas passagens dizem respeito a três grandes temáticas - concepção de sociedade, conceituação filosófica e proposições educacionais - que, dada a natureza do pensamento deweyano, se apresentam sempre entrelaçadas, sendo praticamente impossível separá-las, na maioria das vezes. Na redação do presente trabalho, optou-se por não fragmentar tais assuntos, pois a prioridade aqui não é outra senão compreender a presença dos gregos na composição dos argumentos do autor.

\section{A similaridade e sua superação}

Em Democracia e educação, Dewey utiliza os gregos para estabelecer uma relação de similaridade com a era contemporânea, seja no tocante à ordem social, seja no que diz respeito à educação. ${ }^{4} \mathrm{~A}$ semelhança entre as duas ordens sociais tem por base a noção de "sociedade democrática", que é definida no capítulo 7 do livro como aquela em que existe livre intercâmbio entre os indivíduos, sendo que esse tipo de vida societária se torna inviabilizado quando a coletividade é constituída por interesses divergentes resultantes de diferenças sociais e materiais, circunstância que impele o trabalho a ser exercido de maneira automática, impedindo a comunicação de seus objetivos.

Nesse ponto da argumentação, Dewey (1959, p. 91) menciona que Platão entende ser escravo "o homem que recebe de outro os objetivos que orientam sua conduta". Tal menção serve para afirmar que a sociedade contemporânea não realiza o ideal democrático, pois o que prevalece é o desconhecimento da

${ }^{4}$ Sobre relações de similaridade, analogias e metáforas, ver o capítulo 3 da terceira parte de Perelman e Olbrechts-Tyteca (2002), no qual essas técnicas são identificadas como recursos destinados a fundamentar a estrutura do real. 
utilidade social do trabalho pelo homem que trabalha. A intenção do autor é indicar que na atualidade, embora não haja escravismo, ainda persiste o trabalho que se desenvolve sem o conhecimento de sua real significação pelo homem que o exerce, tal qual o definido pelo filósofo ateniense.

Essa comparação presta-se à análise de que a sociedade atual mais se assemelha a uma máquina do que, propriamente, a uma sociedade. Conforme já foi discutido em estudo anterior (Cunha, 2005b), o raciocínio de Dewey sugere a metáfora "sociedademáquina", representativa da ordem social contemporânea rejeitada pelo autor, uma vez que na atualidade, segundo as suas considerações, inexiste o que é próprio do modo de vida democrático: a plena comunicação entre seus membros.

A mesma argumentação é desenvolvida acerca da educação. No capítulo 19, Dewey (1959, p. 276) discute o antagonismo entre duas formas de educar, uma voltada para o trabalho útil, e outra para uma vida de lazeres, cuja origem é localizada na dicotomia de interesses que "coincide com a divisão em uma classe superior e outra inferior", havendo, em consequiência, "a rígida identificação do trabalho com os interesses materiais, e a do lazer com os interesses ideais". Segundo o autor, portanto, existe íntima relação entre o modo de organização das sociedades e a visão que nelas se desenvolve sobre a educação, existindo, na atualidade, profunda diferenciação entre conhecimento útil e saber contemplativo.

Essa tese é ancorada na similaridade com a sociedade grega, pois foram os problemas estruturais daquela coletividade que levaram Aristóteles a expor, de "modo perfeitamente adequado", que o homem possui uma característica que lhe é própria, "a razão, destinada à contemplação do espetáculo do universo", e também à manutenção do controle sobre "os mais baixos elementos da natureza humana", que são "os apetites e os impulsos ativos e motores" (Dewey, 1959, p. 277).

No capítulo 20 do livro, Dewey (1959, p. 288289) considera que as concepções políticas e filosóficas dos gregos são compreensíveis porque a filosofia ateniense foi iniciada pela "crítica aos costumes e à tradição como padrões para o conhecimento e a conduta". Ao identificarem tais costumes com a experiência, os gregos buscaram colocar a razão em patamar superior ao do mundo sensível, motivo pelo qual, apesar das "grandes divergências, sob muitos pontos de vista, entre estes pensadores" (idem, p. 288), tanto Platão quanto Aristóteles conceberam a experiência como sinônimo de interesses práticos, o que explica o primeiro ter atribuído aos filósofos a tarefa de governar a cidade, uma vez que somente eles possuem atributos racionais para o comando.

Essa mesma apreciação dos antigos é reafirmada no capítulo 21, quando Dewey (1959, p. 306-307) explica que os gregos viam a sua própria sociedade como "arraigada na natureza e sujeita às suas leis", de tal modo que não podiam perceber qualquer "conflito entre o homem e a natureza". Segundo o autor, Platão "faz o conhecimento do homem e da sociedade depender do conhecimento dos aspectos essenciais da natureza", associando "o exame do bem para o homem à consideração sobre o bem ou fim essenciais da própria natureza". Aristóteles "vai mais longe", dizendo que o "mais alto fim do homem não é humano, e sim divino", o que remete ao que é "universal e necessário", motivo pelo qual o conhecimento encontra "matéria mais adequada na natureza do que nas transitórias coisas humanas" (idem, p. 306). ${ }^{5}$

Assim, Dewey admite haver coerência no pensamento grego, em virtude do fato de suas formulações terem sido desenvolvidas no âmbito de uma ordem social desagregada, cujos fins eram vistos como inscritos na "natureza", e não, por oposição, na história. Tornase compreensível, então, que os gregos tenham estabelecido a dicotomia entre a razão e as paixões, o que repercutiu na criação de duas formas de educar: uma para o trabalho, outra para o ócio e a contemplação.

${ }^{5}$ Dewey (1959, p. 309) considera que foi com a educação romana e a escolástica que se perdeu a "tradição grega em que um interesse humanista era empregado como base para o interesse pela natureza”. 
Todo esse raciocínio serve para o autor defender a necessidade de superação de tais similaridades na sociedade contemporânea. Para isso, mostra que o pensamento antigo foi incapaz de distinguir entre o natural e o histórico, razão pela qual Aristóteles identificou o que é tão-somente uma "fase dos costumes sociais" com uma "necessidade natural", daí considerando as "castas necessárias à existência do estado" (Dewey, 1959, p. 318). O Estagirita tinha razão, afirma Dewey (idem, p. 281), ao "admitir a inferioridade e a subordinação da simples habilidade de execução e da simples acumulação de produtos exteriores" perante o "entendimento", mas cometeu um "equívoco teórico" ao presumir a "separação necessária dessas duas coisas". Ocorre que tal equívoco ainda persiste na contemporaneidade, devendo, agora, ser corrigido.

Assim, todo o problema, segundo Dewey, está em continuarmos ainda hoje aceitando aquelas similaridades, ou seja, "tolerando o estado social de coisas que originou e confirmou" aquelas concepções sociais e educacionais. Para superar esse quadro, de nada adiantará "considerar a inteligência um meio de dominar a natureza por intermédio da ação", enquanto persistir o "estado ininteligente e de escravidão para aqueles que diretamente extraem utilidades da natureza" (idem, ibidem).

\section{$O$ recurso às origens $\mathrm{e} a$ contraposição}

Para dar maior solidez a seus argumentos, Dewey recorre à estratégia de localizar o nascedouro dos problemas que se dispõe a tratar, sugerindo que é pelo estudo da origem de alguma coisa que se consegue compreender os seus desdobramentos posteriores e identificar precisamente o que deve ser enfrentado. Esse raciocínio é empregado para firmar a idéia, vista anteriormente, de que a transformação educacional deve ser discutida na esfera da ordem social, pois, para o autor, filosofia, educação e política constituem um só e mesmo problema, cuja solução não pode ser buscada mediante o isolamento de seus componentes.

Essa tese é apoiada numa referência à origem da filosofia, entre os gregos. No capítulo 24 de Demo- cracia e educação, Dewey (1959, p. 363) destaca ser "sugestiva a circunstância de ter-se a filosofia européia originado (entre os atenienses) sob a compreensão direta das questões educacionais". Se a "primitiva história da filosofia" foi "mais um capítulo da história das ciências naturais do que da filosofia, no sentido em que esta palavra é hoje tomada", logo adiante os sofistas "começaram a aplicar os resultados das observações e interpretações dos filósofos da natureza à conduta humana". Naquela ocasião, foi pelo estudo da virtude e das artes políticas que "a filosofia começou a tratar das relações do individual com o universal", buscando responder a indagações acerca da formação do homem no grupo social, o que estabeleceu o pensamento filosófico como "teoria do processo educacional" (idem, p. 364).

Se na origem foi assim, e ainda hoje o é, defende o autor, é também na origem que podem ser identificados os traços da crise atual, a qual precisa ser então enfrentada, já que não foi resolvida em seu nascedouro. Esse tema surge no capítulo 7 por meio de uma referência a Platão, cujas idéias indicavam "que o indivíduo é feliz e a sociedade bem organizada quando cada qual se dedica às atividades para as quais está preparado pelo seu natural", sendo a "primacial tarefa da educação" descobrir a aptidão de cada um e "exercitá-la para ser utilizada eficazmente". Tal concepção, afirma Dewey (1959, p. 97), promoveu a "subordinação da individualidade à organização social”, pois a "superficialidade da idéia platônica" fez "acumular os indivíduos e suas aptidões naturais em poucas classes bem determinadas", quando se sabe que "as aptidões originárias são indefinidamente numerosas e variáveis". ${ }^{6}$

Para defender o valor das instâncias individuais no processo educacional, Dewey recorre novamente aos gregos, elaborando, dessa vez, uma contraposição. Sua tese diz que o conhecimento socialmente útil

\footnotetext{
${ }^{6}$ A mesma crítica aparece no capítulo 23 , que volta a desta-
} car que o erro dessa educação é sua limitada "concepção das vocações necessárias à sociedade" (Dewey, 1959, p. 341). 
é adquirido por meio da experiência e da investigação, processo em que os interesses e as aptidões de cada um são tomados em toda amplitude e variedade. Dewey (1997, p. 355) leva a discussão novamente às origens da filosofia, mais precisamente a Platão, que usa a palavra conhecimento "para designar coisas tão diversas quanto a compreensão pessoal íntima e vital - uma convicção adquirida e testada na experiência - e a identificação feita de segunda mão", a qual, por ser "largamente simbólica", não passa de uma "informação remota desvitalizada”. A essa perspectiva o autor opõe a de Aristóteles, para quem "a virtude moral se assemelha a uma arte como a medicina", priorizando assim a experiência, em detrimento de conhecimentos puramente teóricos (Dewey, 1959, p. 390).

A contraposição entre os dois filósofos serve para Dewey (idem, p. 391) mostrar sua concordância com o Estagirita, dizendo que o aprendizado de segunda mão "não garante a boa conduta, não influi profundamente no caráter", o que só é alcançado quando o conhecimento é "adquirido de primeira mão, mediante as exigências da experiência, que influi de modo significativo na conduta". Tal concordância, porém, é contraposta à concepção aristoteleciana de sociedade, pois Aristóteles entende que "só em um número de pessoas relativamente pequeno é a função da razão capaz de atuar como lei da vida", pois no "comum do povo predominam as funções da vida vegetativa e animal", sendo estes "como os vegetais, os animais e os instrumentos materiais", simples "meios" ou "recursos para atingirem-se fins além delas próprias" (idem, p. 277).

Nessa passagem, Dewey (1997, p. 252-253) destaca que, para Aristóteles, é "por sua natureza, e não apenas pela convenção social", que "existem escravos, isto é, meios para servirem aos fins de outras pessoas". Nessa classificação, continua o autor, incluem-se todos os que são postos "a serviço de fins externos a eles mesmos", sejam os escravos de fato, sejam os artífices, sejam as mulheres, igualmente caracterizados como "instrumentalidades animadas de produção e reprodução dos meios para uma vida livre ou racional".
Recorrer às origens do problema que deseja abordar é a estratégia argumentativa de Dewey para contrapor-se a determinados aspectos do pensamento vigente em sua própria época. Seu discurso tem por objetivo mostrar que, na sociedade contemporânea, ainda persiste a dicotomia entre razão e conhecimento, de um lado, e desejos e necessidades materiais, de outro, ou entre "atividades servis e livres", bem como entre uma educação "baixa ou mecânica" e outra, "liberal ou intelectual" (Dewey, 1959, p. 278).

Por intermédio dos gregos, Dewey mostra também que as filosofias, desde a sua origem histórica, são produtos sociais. O pensamento grego, diz o autor, não resultou das especulações pessoais de um ou outro filósofo: "Se a concepção de Aristóteles representasse unicamente a opinião de Aristóteles, seria ela apenas uma curiosidade histórica mais ou menos interessante". O fato é que o Estagirita "unicamente descreveu com clarividência, e sem a infidelidade sempre resultante da confusão mental, o espetáculo da vida que tinha à sua frente" (idem, $\mathrm{p}$. 280). Por isso, a educação grega não é fruto da imaginação ou do desvario dos gregos, mas constitui um conjunto de práticas coerente com a sua vida social, tendo gerado "notáveis frutos" por nunca se ter desviado "para uma separação impossível entre o espírito e o corpo" (idem, p. 154).

O que se conclui dessas considerações é que, na visão do autor, a filosofia grega (como as demais, aliás) foi elaborada dentro dos limites e das necessidades de sua ordem social. Ao estabelecer sua contrariedade perante o pensamento grego, Dewey quer mostrar que a superação de problemas filosóficos só é possível quando outras necessidades, também sociais, se apresentam. Não havendo tais demandas, não há alicerce para uma nova filosofia, e foi esse o caso da Grécia. Dewey não se contrapõe à filosofia grega no contexto próprio em que ela se desenvolveu, pois o seu objetivo é fazer a crítica da persistência, na contemporaneidade, daquelas idéias e práticas sociais. ${ }^{7}$

${ }^{7}$ No capítulo 9 há um exemplo desse procedimento. Dewey (1959, p. 130) afirma que, onde há "subordinação das atividades 
Quanto a isso, o autor afirma que aquela visão de sociedade, de homem e de educação só poderá ser plenamente substituída quando forem superadas as idéias e as práticas sociais que, desde a origem, distribuem desigualmente os conhecimentos entre as diversas classes sociais, ou seja, quando houver uma sociedade verdadeiramente democrática em que todos "tomem parte em serviços de utilidade prática e todos desfrutem nobres ócios" (idem, p. 282).

\section{A dissociação de noções e os pares filosóficos}

Ao analisar o pensamento filosófico, Dewey utiliza uma técnica muito comum na estruturação de discursos persuasivos: a dissociação de noções. ${ }^{8}$ Quando um orador deseja enfatizar a prioridade de determinado elemento perante outro, o que lhe parece preferível é firmado como critério para julgar aquele cujas características pretende menosprezar. Assim se dá, exemplarmente, com o par antitético e classificatório "aparência-realidade", do qual podem decorrer outros, como "irracional-racional", "subjetivo-objetivo", em que o segundo termo atua sempre como parâmetro de julgamento do primeiro. ${ }^{9}$

O par deweyano é formado pelos termos "teoriaprática”, pois o que o autor busca verificar nas filosofias que analisa são as respostas que oferecem às demandas sociais concretas, e não o seu valor enquanto puros enunciados teóricos. Por meio desse recurso, Dewey estabelece a inferioridade da filosofia grega

individuais às classes detentoras da autoridade, existe o risco de ser a educação industrial dominada pela conformidade ao status quo, o que leva as "oportunidades econômicas" a determinarem as profissões das pessoas. E completa: nesse caso, o que se tem é o "ressurgir dos defeitos do plano de Platão, sem seu inteligente método de seleção".

${ }^{8}$ O capítulo 4 da terceira parte de Perelman e OlbrechtsTyteca (2002) é todo dedicado a essa técnica.

${ }^{9}$ A critério de quem enuncia o discurso, esses pares podem, evidentemente, ser invertidos, do que resultarão outras ordens argumentativas. ante a moderna, particularmente por a segunda estabelecer a experiência e a investigação como sustentáculos privilegiados do conhecimento, o que não foi feito pela primeira. Embora ambas sejam reconhecidas como teoricamente coerentes, só a mais recente trouxe conseqüências práticas apreciáveis.

No capítulo 11 de Democracia e educação encontra-se uma célebre formulação dos gregos, que figura no Mênon de Platão, segundo a qual, quando buscamos alguma coisa, é porque ou já sabemos o que está sendo buscado, e então não há por que buscar, ou nada sabemos, o que nos impede de encontrar o que estamos procurando. Dewey (1959, p. 162) contradiz esse dilema, afirmando que sua formulação "não abre margem para o vir a saber, para o aprender", dado que presume ou "o conhecimento completo, ou a completa ignorância", o que, por sua vez, restringe a possibilidade da investigação e da reflexão. ${ }^{10}$ Essa crítica pretende valorizar o pensamento moderno, que possibilita "conclusões hipotéticas" e sucessivas "tentativas de obtenção de resultados", caracterizados como meios decisivos para o conhecimento científico.

Dewey (1959, p. 293) alude à distinção platônica entre a experiência e a razão, na qual a segunda "significava romper com as limitações do costume e verem-se as coisas como realmente eram", ao passo que a primeira traduzia "hábitos, costumes, ou conservação do produto de uma série de casuais experiências anteriores". Já os modernos, diz o autor, conceberam a razão como "formas vazias que precisariam ser enchidas pela experiência, pelas impressões sensoriais", para adquirirem significado, representando a experiência um "rompimento com a autoridade", um "franquear-se às novas impressões", uma "ânsia de descobrir e inventar", uma "irrupção no espírito, das coisas como realmente eram, livres do véu com que as idéias preconcebidas as recobriam".

No dizer do autor, o que confere superioridade prática ao pensamento moderno é esse caráter revela-

${ }^{10}$ No presente trabalho, todas as expressões entre aspas são dos textos citados. 
dor da "realidade" das coisas - as coisas como "realmente são" -, viabilizado pelo método científico de investigação e prova, embora não se possa negar a qualidade formal ou teórica da filosofia grega. O problema do pensamento grego, segundo Dewey (1959, p. 322), foi ter considerado que "o pensamento era livre quase até o ponto de chegar-se a desvairadas especulações", pois sem o uso do método experimental era impossível ver as experiências individuais como passíveis de retificação pelas investigações de outros. ${ }^{11}$ Embora sejam "um belo fragmento de lógica formal", ou seja, formulações teóricas bem articuladas, Dewey (idem, p. 163) considera que as teses gregas foram superadas pelo potencial de aplicabilidade propiciado pela visão de ciência surgida na modernidade.

Quando os modernos fizeram a "inversão quase completa da doutrina clássica sobre as relações entre a experiência e a razão", conseguiram superar os impedimentos à investigação, levando os "conhecimentos armazenados" a tornarem-se "simples meios para aprender, para descobrir" (idem, p. 292-293). Foi essa inversão que permitiu os inúmeros progressos materiais verificados na era moderna, como também no mundo contemporâneo, representados, em última instância, pela ciência.

\section{A garantia, o apoio e a refutação}

O discurso do autor, conforme exposto anteriormente, pode ser formalmente expresso como segue, em consonância com o "layout de argumentos" proposto por Toulmin (2001). ${ }^{12}$ Da constatação de que os modernos valorizaram a experiência e a investigação, Dewey extrai a tese de que é possível obter conhecimento verdadeiro por meio da experiência e da in-

${ }^{11}$ Nesse trecho, como em outros, o autor faz uso da técnica da generalização, equiparando os gregos aos medievais, para quem o indivíduo não passava de "um instrumento por cujo intermédio se manifestava uma inteligência divina e universal".

${ }^{12}$ A aplicação desse modelo de análise do silogismo pode ser bem visualizada no trabalho de mestrado de Costa (2005). vestigação. Considerando que a referida constatação é um "dado" e que a afirmação final é uma "conclusão", pode-se dizer que a passagem do primeiro à segunda é sustentada por uma "garantia", qual seja, a de que os modernos elaboraram formulações corretas ou mais acertadas do que outras, como a dos gregos, no exemplo em pauta.

Para melhor visualização, esses enunciados e os que serão apresentados a seguir podem ser dispostos graficamente, como no quadro "Layout do argumento de John Dewey". ${ }^{13}$

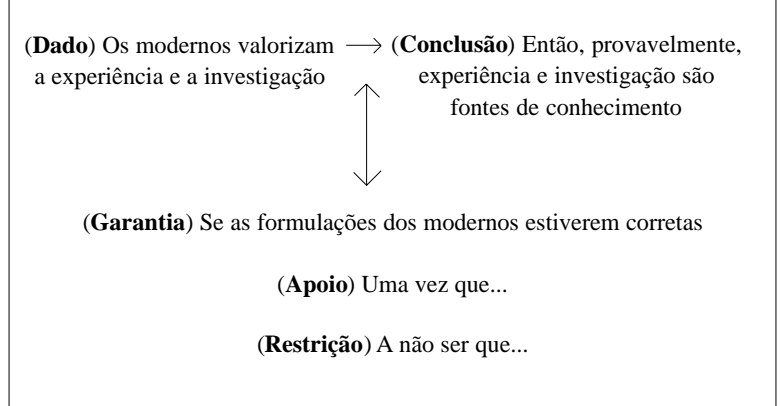

A afirmação da "correção" da filosofia moderna requer, no entanto, determinados "apoios" argumentativos, os quais não se encontram senão em formulações persuasivas, ou seja, em argumentos capazes de levar o auditório - no caso, os leitores - a dar assentimento ao enunciado da "garantia". No discurso deweyano, o "apoio" da "garantia" é justamente o que foi apresentado anteriormente, fundamentado no par "teoria-prática": tendo organizado idéias em conformidade com as demandas da ordem social moderna, as "teorias" dos pensadores modernos podem ser qualificadas como corretas porque resultaram em notáveis avanços no âmbito da vida "prática".

Nesse modo de análise da forma silogística, a "conclusão" deve sempre vir na condicional, indicando tratar-se de um enunciado "possível", e não "necessário", uma vez que se firma numa premissa - a maior, que atua como "garantia" - cujo "apoio" argumentativo necessita ser desenvolvido. Mais ainda, esse "apoio"

${ }^{13}$ A elaboração desse quadro é baseada no modelo que se encontra no capítulo 4 de Toulmin (2001). 
precisa mostrar-se resistente a "restrições" ou "refutações", uma vez que a "conclusão" será tida como válida, sustentada na "garantia" e em seu "apoio", a não ser que algo se apresente a título de abalar este último. A exemplo da "conclusão", o "apoio" e a "refutação" também não se apresentam em termos categóricos, pois são enunciados no âmbito de um confronto dialético entre os interlocutores, ocasião em que podem ser alvo de controvérsias. ${ }^{14}$

Assim, considerando que a argumentação da "garantia" de Dewey seja convincente, resta verificar se não há nenhuma "restrição" capaz de refutá-la, o que, em situações dialéticas, é tarefa do interlocutor interessado em combater a tese do orador com quem se defronta. Em Democracia e educação, no entanto, observa-se uma curiosa manobra discursiva, pois é o próprio autor quem interpõe restrições à argumentação por ele mesmo oferecida para sustentar a "garantia" de sua “conclusão". Esse procedimento encontrase na passagem em que Dewey (1959, p. 293) explica que a radical mudança de perspectiva ocasionada pelos modernos produziu resultados indesejáveis, pois a experiência perdeu "a significação prática que tivera desde os tempos de Platão", deixando de "significar meios de fazer e realizar" para tornar-se "o nome de qualquer coisa intelectual e cognitiva".

Para Dewey (1959, p. 294), então, a conseqüência prática ocasionada pelo "empirismo filosófico e pela corrente contrária a ele" - o racionalismo, por certo foi tornar-se a experiência "um meio de adquirir conhecimentos", do que resultou "um 'intelectualismo' ainda maior do que o da filosofia antiga". Na educação, particularmente, a moderna valorização da experiência "levou a considerar o espírito como sendo puramente receptivo", numa tendência que transformou o empirismo em simples sensacionismo.

${ }^{14} \mathrm{O}$ "dado" não carece do qualificativo condicional, pois é supostamente baseado em elementos empíricos. Sua contestação, entretanto, também pode ser feita, mas para isso é preciso empregar recursos igualmente empíricos, diferentes dos que são acionados para refutar a "garantia".
Tais considerações atingem diretamente o cerne do argumento deweyano que sustenta a possibilidade de obter conhecimento por intermédio da experiência, todo ele assentado na premissa de que os modernos elaboraram concepções "corretas". Ora, negar a "correção" de tais concepções implica "refutar" a "garantia", impedindo validar a afirmação final. ${ }^{15}$ Essa refutação é feita com base no par "teoria-prática", pois o que Dewey tem em vista não são os enunciados filosóficos modernos em seu aspecto formal, mas o seu potencial de aplicabilidade aos problemas sociais, ou seja, o modo como a filosofia moderna foi concretamente transposta para o terreno das demandas concretas da realidade. Segundo o autor, no campo da "prática" as filosofias modernas tornaram-se impotentes, por teremse convertido em atividades mecanicistas.

\section{Os pares filosóficos conflitantes}

O que permite a Dewey considerar a filosofia moderna impotente, do ponto de vista prático, é uma análise crítica do mais destacado produto da modernidade: a ciência. Tal análise é feita por meio do par "teoria-prática" aliado a dois outros pares, opostos e conflitantes, formados pelos termos "material" e "intelectual", com os quais são caracterizadas tanto a ciência antiga quanto a moderna. A função desses pares é representar o dualismo incapacitante não só da modernidade, mas de toda a tradição filosófica, dada como vigente ainda na contemporaneidade, de maneira que se coloque em pauta a proposição fundamental do autor acerca da necessidade de uma "reconstrução da filosofia". ${ }^{16}$

15 Tecnicamente, uma restrição deve abalar o termo médio do silogismo, pois é por intermédio desse termo que se enuncia a conclusão. Nesse caso, o termo médio é a "correção" das formulações modernas, que é empregada pelo autor para validar o enunciado de que a experiência é fonte de conhecimento.

${ }^{16}$ Esse tema é explorado pelo autor no livro Reconstrução em filosofia, publicado poucos anos depois de Democracia e educação. 
O ponto de partida de Dewey (1959, p. 209) é uma conceituação de ciência, como se vê no capítulo 14 de Democracia e educação, no qual consta que ciência "consiste nos instrumentos e métodos especiais" elaborados pela humanidade "com o fim de orientar a reflexão sob condições tais que são verificados seus processos e resultados". Ciência, diz o autor, é uma "arte criada", "não espontânea", na qual residem os "melhores instrumentos que a humanidade inventou para orientar eficazmente o raciocínio".

Semelhante qualificação encontra-se no capítulo 17, no qual Dewey (1959, p. 241) esclarece que a ciência é "aquele saber proveniente dos métodos de observação, reflexão e verificação deliberadamente adotados para assegurar conhecimentos certos e provados", mediante um "esforço inteligente e perseverante para rever as convicções correntes a fim de excluir delas o que é errôneo, aumentar-lhes a exatidão". "Lógica e pedagogicamente a ciência é a perfeição do conhecimento, é sua última fase", diz o autor, concluindo: ciência "significa compreensão do conteúdo lógico de todo o conhecimento".

No capítulo 15 do livro, Dewey (1959, p. 215) recorre novamente aos gregos, utilizando outra vez o argumento da origem para precisar o sentido que confere ao termo ciência. Menciona, então, que a palavra grega techné foi utilizada, "até o raiar da consciência filosófica", para designar tanto a arte quanto a ciência, e acrescenta que Platão "explicou a noção do saber baseando-se em uma análise dos conhecimentos dos sapateiros, músicos etc.”, ocupações ou artes que encerram "um fim, o domínio do material ou da coisa a que se aplicavam a atividade, o comando dos instrumentos e uma determinada ordem no trabalho", constituindo-se, assim, como "artes inteligentes".

Somada ao que consta nos capítulos 14 e 17, essa referência a Platão serve para estabelecer os dois elementos que, segundo o autor, tornam a ciência o que é, permitindo-lhe concretizar objetivos práticos: a ciência é formada por meios e fins, um componente estritamente material ou instrumental e um componente intelectual, sendo que ambos, quando devidamente integrados, contribuem para a obtenção de conhecimentos certos e provados.
O raciocínio de Dewey sugere a possibilidade de serem constituídos dois pares filosóficos com os mesmos termos: quando houver supremacia dos recursos instrumentais ante o aparato da inteligência que determina os fins da atividade científica, forma-se o par "intelectual-material", ao passo que, na situação inversa, tem-se o par "material-intelectual". São pares que se opõem um ao outro, cada qual definindo um modo de conceber a ciência, e tanto um quanto o outro expressam situações de incompletude que tornam estéril aquilo que definem, pois os benefícios da atividade científica, segundo o autor, só advêm da integração entre os dois termos.

Ao analisar os avanços científicos contemporâneos, Dewey (1959, p. 246) qualifica-os como "puramente técnicos", uma vez que propiciaram "meios mais eficazes de satisfazer desejos preexistentes", sem modificar "a natureza dos objetivos humanos". Assim, o autor vê, na atualidade, a predominância dos meios sobre os fins, ou seja, a hegemonia do par "intelectual-material", contrariando a referida integração entre os termos. ${ }^{17}$ Embora diga que não há "civilização moderna alguma que, sob todos os pontos de vista, seja igual à cultura grega", Dewey (idem, p. 312313) não pretende enaltecer nem a ciência antiga nem a medieval, pois entende que ambas cometiam o equívoco de aceitar "o mundo em sua variedade qualitativa", considerando "os processos da natureza como tendo fins", como "teleológicos" (idem, ibidem), o que significa que se deixavam guiar pela prevalência do par "material-intelectual", igualmente contrariando o ideal de equilíbrio entre os dois termos.

O par "intelectual-material" é associado a outros, como "qualidade-quantidade" e "subjetividade-

\footnotetext{
${ }^{17}$ Nessa passagem, Dewey utiliza novamente os gregos como contraponto, afirmando que não há "civilização moderna alguma que, sob todos os pontos de vista, seja igual à cultura grega”. A frase, um tanto obscura, parece referir-se à recenticidade da ciência contemporânea, pois o autor considera que a ciência "é ainda excessivamente recente para se ter incorporado às atitudes imaginativas e emocionais dos homens".
}

Revista Brasileira de Educação $\quad$ v. 12 n. 35 maio/ago. 2007 
objetividade", como se nota na seguinte crítica de Dewey (1997, p. 284) aos modernos: "Sons, cores, fins, tanto bons quanto ruins, foram julgados como puramente subjetivos - como meras impressões na mente", sendo a existência objetiva relacionada unicamente a "aspectos quantitativos". O pensamento moderno, diz o autor, privilegiou "a uniformidade, e não a diversidade", supondo que "o ideal era a descoberta de uma fórmula matemática única, aplicável diretamente a todo o universo, fórmula de que se pudesse deduzir toda a aparente variedade dos fenômenos", do que resultou uma "filosofia mecanista" (Dewey, 1959, p. 313).

Assim, nem a filosofia antiga nem a moderna conseguiram sustentar o ideal de ciência como atividade integradora e integrada. Enquanto a primeira foi absorvida pelos fins, a que Dewey vincula os termos qualidade e variedade, o pensamento moderno privilegiou os meios, termo que vem acompanhado dos atributos quantidade e uniformidade. $\mathrm{O}$ critério do autor para rejeitar tanto o par "material-intelectual" dos antigos quanto o seu oposto, característico dos modernos, é o par "teoria-prática", pois, embora munidas de enunciados teoricamente bem formulados, ambas as filosofias se tornaram impotentes para responder às exigências práticas postas às ciências que originaram. Conforme foi dito anteriormente, é por intermédio desse argumento que Dewey sugere a necessidade de uma nova filosofia.

\section{Considerações finais}

A investigação feita neste trabalho sobre Democracia e educação, de John Dewey, revela que o autor faz menção à vida social e às concepções filosóficas dos gregos da era clássica em várias circunstâncias, seja para tratar de assuntos propriamente filosóficos, seja para analisar temas relacionados a política e educação. Em nenhum momento o livro deixa transparecer o intuito de promover a desqualificação gratuita dos costumes, das idéias ou da ordem social vigentes em Atenas, pois as referências do autor àquele momento histórico vêm invariavelmente acompanhadas do empenho em situar o contexto dos elementos que analisa.

Perante os gregos, Dewey não elabora uma descontextualização no sentido próprio, o que ocorreria se olhasse para aquela época sem considerar os seus condicionantes políticos, sociais e intelectuais. Tampouco faz um estudo desinteressado, pois todas as suas análises sobre a Grécia são guiadas por um único objetivo, que é colocar em cena as idéias que ele mesmo defende acerca do mundo contemporâneo. O autor efetua, assim, uma recontextualização, ou seja, toma as problemáticas do tempo antigo e delas servese para abordar assuntos que dizem respeito ao tempo moderno e, principalmente, ao contemporâneo.

No livro de Dewey, os argumentos são organizados de maneira que postulem que os gregos não conseguiram solucionar as contradições inerentes à sua sociedade, o que resultou na impossibilidade de superarem, no plano do pensamento, a dicotomia entre experiência e razão, o que repercutiu em suas práticas científicas. Nesse aspecto, o autor serve-se dos antigos para refletir sobre os modernos, aplicando a ambos o mesmo diagnóstico, pois a modernidade, segundo entende, também não logrou sustentar uma filosofia integradora de meios e fins, dando margem a uma concepção mecanicista de ciência. Sendo assim, a argumentação de Dewey, tanto sobre os pensadores da Grécia clássica quanto sobre os da modernidade, resulta na tese de que é preciso elaborar uma nova visão filosófica que supere as dicotomias ainda vigentes na contemporaneidade.

Como foi possível observar neste trabalho, o autor dialoga com seu auditório por meio de estratégias discursivas compostas por similaridades e contraposições, apropriando-se dos gregos de variadas maneiras, ora para apontar suas limitações, ora para opôlos ao pensamento moderno. Nesse discurso, o lance decisivo, e também o mais surpreendente, é a retirada do "apoio" - segundo a terminologia aqui empregada - à "garantia" do enunciado sobre a superioridade da filosofia moderna, o que atinge diretamente o cerne da herança legada pela modernidade, que é o valor conferido à ciência dela resultante. 
Com isso, Dewey pavimenta o caminho para sustentar que só uma nova filosofia pode dar sentido a uma ciência contemporânea, na qual a experiência e a investigação se apresentem de fato como meios confiáveis para o conhecimento. ${ }^{18}$ Conforme já foi observado anteriormente (Cunha, 2007), o autor dedica os dois últimos capítulos de Democracia e educação a esse tema, discutindo especificamente as concepções de conhecimento e moral que, segundo julga, devem servir de fundamento a essa filosofia reconstruída.

Pelos termos em que o assunto é tratado no livro, nota-se que Dewey mantém fidelidade ao par "teoria-prática", pois não faz explanações de princípios cabais e sistemáticas, "teóricas", por assim dizer. Ao contrário, suas expressões envolvem uma noção de temporalidade, o tempo presente, incentivando o homem a tomar parte nas circunstâncias "práticas" da vida, considerando que conhecimento "não é apenas algo de que temos consciência agora, mas consiste nas disposições que conscientemente usamos para entender o que acontece agora". Essa formulação, que Dewey (1997, p. 244) denomina "pragmática", alude tão-só a um posicionamento do sujeito, determinado não pelo "ter", mas pelo "uso" que faz da consciência para conhecer, o que remete a um contexto de ação. ${ }^{19}$ Em vez de uma definição "teórica", o autor oferece um significado "prático" de conhecimento: é o que traz "algo de nossas disposições à consciência com o fim de corrigir uma perplexidade, por meio do entendimento da conexão entre nós e o mundo em que vivemos" (idem, p. 344).

Em suas reflexões finais sobre a educação, notase o mesmo par "teoria-prática", uma vez que a filosofia adequada à contemporaneidade é descrita por Dewey (1997, p. 360) como devendo ser permeada por uma

${ }^{18}$ Esse tema é desenvolvido pelo autor, mais tarde, em seu livro A busca da certeza (ver Cunha, 2006).

${ }^{19}$ A palavra pragmatic deriva do latim pragmaticus, cuja origem grega é pragmatikos, relacionada a pragma, que alude a ação, vocábulo associado ao segundo termo do par "teoria-prática". concepção moral que confira ao homem o "poder de tomar parte na vida social", viabilizando um caráter voltado ao "contínuo reajustamento que é essencial ao crescimento". A educação, portanto, também não recebe do autor um tratamento sistemático, em que se veria sustentada por um conjunto de fundamentos epistemológicos. Na visão deweyana, educar é formar indivíduos capazes de agir criticamente na vida social e reajustar seus valores na medida em que se defrontam com os problemas concretos de sua época.

O que se pode concluir da proposta contida no livro de Dewey é que, no mundo contemporâneo, a filosofia e a educação, esses termos gêmeos, precisam vincular-se ao contexto social atual, de maneira que suas proposições se façam efetivas perante os problemas do tempo presente. Só assim a experiência e a investigação poderão realmente se consolidar como meios de conhecimento. Para que isso se realize, deve haver um "interesse moral" em "aprender com todos os contatos da vida" (Dewey, 1997, p. 360).

\section{Referências bibliográficas}

AMARAL, Maria Nazaré P. C. Dewey: filosofia e experiência democrática. São Paulo: Perspectiva/Universidade de São Paulo, 1990. COSTA, Viviane. Argumentos católicos contra John Dewey: análise retórica do discurso de oposição à pedagogia nova. 2005. Dissertação (Mestrado em Educação Escolar) - Faculdade de Ciências e Letras, Universidade Estadual Paulista, Araraquara, 2005. CUNHA, Marcus Vinicius. John Dewey: uma filosofia para educadores em sala de aula. Petrópolis: Vozes, 1994.

John Dewey: a utopia democrática. Rio de Janeiro:

DP\&A, 2001.

Recontextualização e retórica na análise de discursos pedagógicos. In: SOUZA, Rosa Fátima; VALDEMARIN, Vera Teresa (Orgs.). A cultura escolar em debate: questões conceituais, metodológicas e desafios para a pesquisa. Campinas: Autores Associados, 2005a. p. 179-207.

Comunicação e arte, ou a arte da comunicação, em

John Dewey. Revista Brasileira de Estudos Pedagógicos, Brasília, v. 86 , n. $213 / 214$, p. 9-20, maio/dez. 2005 b.

John Dewey, o dragão cético. Educação e Cultura

Contemporânea, Rio de Janeiro, v. 3, n. 6, p. 45-63, jul.-dez. 2006. 
. Leituras e desleituras da obra de John Dewey. In: BENCOSTA, Marcus Albino Levy. Culturas escolares, saberes e práticas educativas: itinerários históricos. São Paulo: Cortez, 2007. DEWEY, John. Democracia e educação: introdução à filosofia da educação. 3. ed. Trad. Godofredo Rangel e Anísio Teixeira. São Paulo: Nacional, 1959.

Democracy and education: an introduction to the philosophy of education. Nova York: The Free Press, 1997.

MURPHY, John. O pragmatismo: de Peirce a Davidson. Trad. Jorge Costa. Codex (Portugal): Asa, 1993.

PERELMAN, Chaïm; OLBRECHTS-TYTECA, Lucie. Tratado da argumentação: a nova retórica. Trad. Maria Ermantina Galvão. São Paulo: Martins Fontes, 2002.

TOULMIN, Stephen. Os usos do argumento. Trad. Reinaldo Guarany. São Paulo: Martins Fontes, 2001.

MARCUS VINICIUS DA CUNHA, doutor em educação pela Universidade de São Paulo (USP) e livre-docente em psicologia da educação pela Universidade Estadual Paulista (UNESP), é professor associado da Faculdade de Filosofia, Ciências e Letras de Ribeirão Preto/USP e pesquisador do Conselho Nacional de Desenvolvimento Científico e Tecnológico (CNPq). Estuda o desenvolvimento das idéias pedagógicas no Brasil entre as décadas de 1930 e 1950, dedicando-se especialmente à influência de John Dewey nesse período. Coordena o grupo de pesquisa "Retórica e Argumentação na Pedagogia", cujo objetivo é desenvolver uma metodologia para a análise de discursos educacionais. Publicações: John Dewey, uma filosofia para educadores em sala de aula (Rio de Janeiro:Vozes, 1994); John Dewey, the other face of the Brazilian New School (Studies in Philosophy and Education, v. 24, n. 6, p. 455-47, nov. 2005); Educação e arte, ou a arte da comunicação, em John Dewey (Revista Brasileira de Estudos Pedagógicos, v. 86, p.9-2,n.213/214,maio/dez.2005).E-mail:mvcunha@yahoo.com

LEONARDO FREITAS SACRAMENTO, aluno do curso de Pedagogia da Faculdade de Filosofia, Ciências e Letras de Ribeirão Preto/ Universidade de São Paulo (USP), é bolsista de iniciação científica do Conselho Nacional de Desenvolvimento Científico e Tecnológico (CNPq) desde 2004, desenvolvendo pesquisa sobre a filosofia grega em obras de John Dewey. Apresentou o trabalho "A presença dos gregos na obra de John Dewey" no I Seminário Internacional em Educação e Filosofia, realizado na Universidade Estadual Paulista (UNESP) de Marília em 2006 (publicado em CD-ROM organizado por P. A. Pagni). E-mail: pedagogiausprp@yahoo.com.br

Recebido em outubro de 2006 Aprovado em fevereiro de 2007 